\title{
INFLUÊNCIA DA DIMINUIÇÃO DA ÁREA FOLIAR NA PRODUTIVIDADE E NA DURAÇÃO DO CICLO DA VIDEIRA 'NIAGARA ROSADA' $\left({ }^{1}\right)$
}

\author{
MÁRIO JOSÉ PEDRO JÚNIOR (2, $)$, CELSO VALDEVINO POMMER (3,6), \\ FERNANDO PICARELLI MARTINS ( $)$ e IVAN JOSÉ ANTUNES RIBEIRO (5,6)
}

\begin{abstract}
RESUMO
Avaliou-se o efeito da điminuiçāo da área foliar, na produção e na duraçāo do ciclo da videira 'Niagara Rosada', pelos seguintes niveis de desfolha dos ramos: $0,15,30,50$ e $70 \%$. No caso da desfolha mais drástica, a produção diminuiu $77 \%$ e a duraçăo do ciclo aumentou vinte dias. A manutenção de, pelo menos, $85 \%$ da área foliar, não afetou a produção, mas aumentou três dias a duração do ciclo. Para representar a influência da desfolha, são apresentadas curvas da função logística para a produção e đa quadrática para a duração do ciclo.
\end{abstract}

Termos de indexação: videira, 'Niagara Rosada', desfolha, duraçāo de ciclo, produçāo.

\section{ABSTRACT \\ INFLUENCE OF LEAF REMOVAL ON YIELD AND CYCLE DURATION OF 'NIAGARA ROSADA' GRAPEVINES}

\begin{abstract}
The effect of leaf removal on yield and cycle duration of 'Niagara Rosada' grapevines was evaluated by defoliation $(0,15,30,50$ and $70 \%$ of leaf removal), in an experiment carried out at the Jundiaí Experimental Station (São Paulo State, Brazil). Vines with $30 \%$ of the leaves (defoliation of $70 \%$ ) had $77 \%$ lower crop yields and the cycle was lenghtned by 20 days. Defoliation of $15 \%$ did not affect grape yield but increased three days in cycle duration when compared to the control treatment (no defoliation). The best curve fitness of the effect of defoliation on yield was the logistic and on cycle duration was the quadratic function.
\end{abstract}

Index terms: grapes, 'Niagara Rosada', defoliation, cycle duration, yield.

\section{INTRODUÇÃO}

A videira 'Niagara Rosada', a mais cultivada na regiāo produtora de uva de mesa de Jundiaí (SP), é normalmente conduzida no sistema de espaldeira com três fios de arame. Com o uso desse sistema, a diminuição de área foliar fotossinteticamente ativa, causada por doenças foliares, pode levar à perda de produtividade e a alterações na qualidade do produto.

O efeito da diminuição da área foliar na produtividade da planta, no seu desenvolvimento e na composição da uva, pode ser observado por estudos de desfolha controlada.

\footnotetext{
(1) Recebido para publicação em 5 de agosto de 1991 e aceito em 7 de fevereiro de 1992.

(') Seção de Climatologia Agrícola, Instituto Agronômico (IAC), Caixa Postal 28, 13001-970 Campinas (SP).

(3) Seção de Viticultura, IAC.

() Estação Experimental de Jundiaí, IAC.

(5) Seção de Fitopatologia, IAC.

() Com bolsa de pesquisa do CNPq.
} 
May et al. (1969), trabalhando com a videira cultivar Sultania, removeram, trinta dias após a antese, $2 / 3$ e $1 / 3$ das folhas, e a produçāo foi reduzida 35 e $10 \%$ respectivamente, existindo ainda efeito na produção do ano seguinte pela redução do número de cachos por ramo.

O efeito da época e da severidade da desfolha no crescimento e na composiçāo da uva, cultivar Thompson Seedless, foi analisado por Kliewer (1970), que mostrou que folhas retiradas nas proporções de 25 e $50 \%$, doze dias após a antese, prejudicaram a produção, diminuindo-a 28 e $34 \%$ respectivamente. Posteriormente, Kliewer \& Antcliff (1970), iniciando a retirada das folhas trinta dias depois da antese, notaram a redução no peso das bagas em todos os tratamentos de eliminação de folhas, sendo a retirada das apicais mais prejudicial que a das basais.

Peterson \& Smart (1975), trabalhando com o cultivar Shiraz, não notaram influência da época da remoção das folhas e informaram que a manutenção de seis folhas por ramo não influiu na produtividade, porém duas folhas por ramo foi considerado um tratamento muito severo, diminuindo $12,4 \%$ a produçāo.

Mais recentemente, porém, Bledsoe et al. (1988), ao estudar o efeito da época e da severidade de desfolha na produtividade do cultivar Sauvignon Blanc, não encontraram diferenças entre os tratamentos, ou seja, os níveis e a época de desfolha nāo afetaram a produtividade.

A redução da área foliar, para simular os danos causados pelo ataque de insetos, foi utilizada por Parra (1975), que, mediante eliminação de 25,50 e $75 \%$ da área foliar em cafeeiros, avaliou os danos que seriam causados por igual intensidade de ataque por Perileucoptera coffeella.

O presente trabalho foi desenvolvido com o objetivo de avaliar o efeito da perda de área foliar provocada pelo ataque de pragas e doenças, simulado por meio de desfolha artificial, na produtividade e na duração do ciclo da videira 'Niagara Rosada'.

\section{MATERIAL E METODOS}

O experimento foi instalado em vinhedos de 'Niagara Rosada' com quatro anos de idade, na Estação Experimental de Jundiaí (latitude: $23^{\circ} 12$ 'S, longitude: $46^{\circ} 52^{\prime} \mathrm{W}$ e altitude: $715 \mathrm{~m}$ ) do Instituto Agronômico.
Os tratamentos constaram da desfolha manual a partir da parte apical, ficando os ramos com: 6 (controle), 5, 4, 3 e 2 folhas, representando, respectivamente, cerca de $0,15,30,50$ e $70 \%$ de desfolha. Esta foi iniciada na fase de pré-florescimento e repetida semanalmente.

A videira foi conduzida em espaldeira com três fios de arame, sob regime de poda curta, despontando-se os ramos quando atingiam a altura de $10 \mathrm{~cm}$ acima do terceiro fio. $O$ desnetamento foi semanal durante o período do experimento e os tratos culturais (adubaçāo, cobertura morta, pulverizações) seguiram o esquema normal utilizado pelos viticultores da regiāo, não tendo sido feito desbaste de cachos.

Os tratamentos, dispostos em parcelas que constavam de três plantas, sendo a central a planta útil, foram instalados em blocos ao acaso com cinco repetições, em 1988, 1989 e 1990. Ao final do ensaio, avaliaram-se: (a) duração do ciclo (poda-colheita) e (b) produtividade (grama/planta). Efetuava-se a colheita quando a uva atingia o ponto de maturação para o comércio, sendo a data de colheita a média entre as várias datas das colheitas parciais.

$\mathrm{Na}$ análise estatística, utilizou-se o programa estatístico SANEST para a análise da variância, o teste de Duncan para médias e a descrição das curvas pelo programa para microcomputadores desenvolvido por Zullo Jr. \& Arruda (1987).

\section{RESULTADOS E DISCUSSÃO}

Os valores médios de produtividade (grama/planta) e de duração do ciclo para cada tratamento de desfolha, correspondentes a aproximadamente 0 , $15,30,50$ e $70 \%$ de desfolha, encontram-se no quadro 1.

A análise da variância mostrou diferença entre os tratamentos tanto para a produção quanto para a duração do ciclo. Os tratamentos 0 e $15 \%$ de desfolha não mostraram diferença na produção, tendo sido encontrado um aumento estatisticamente significativo de três dias na duração do ciclo. Praticamente, a perda de cerca de $15 \%$ da área foliar ativa não influiu na produção e na duração do ciclo.

Quando o nível de desfolha foi maior (tratamentos com 30,50 e $70 \%$ de desfolha), a queda de produção foi mais acentuada, atingindo valores de $77 \%$ 

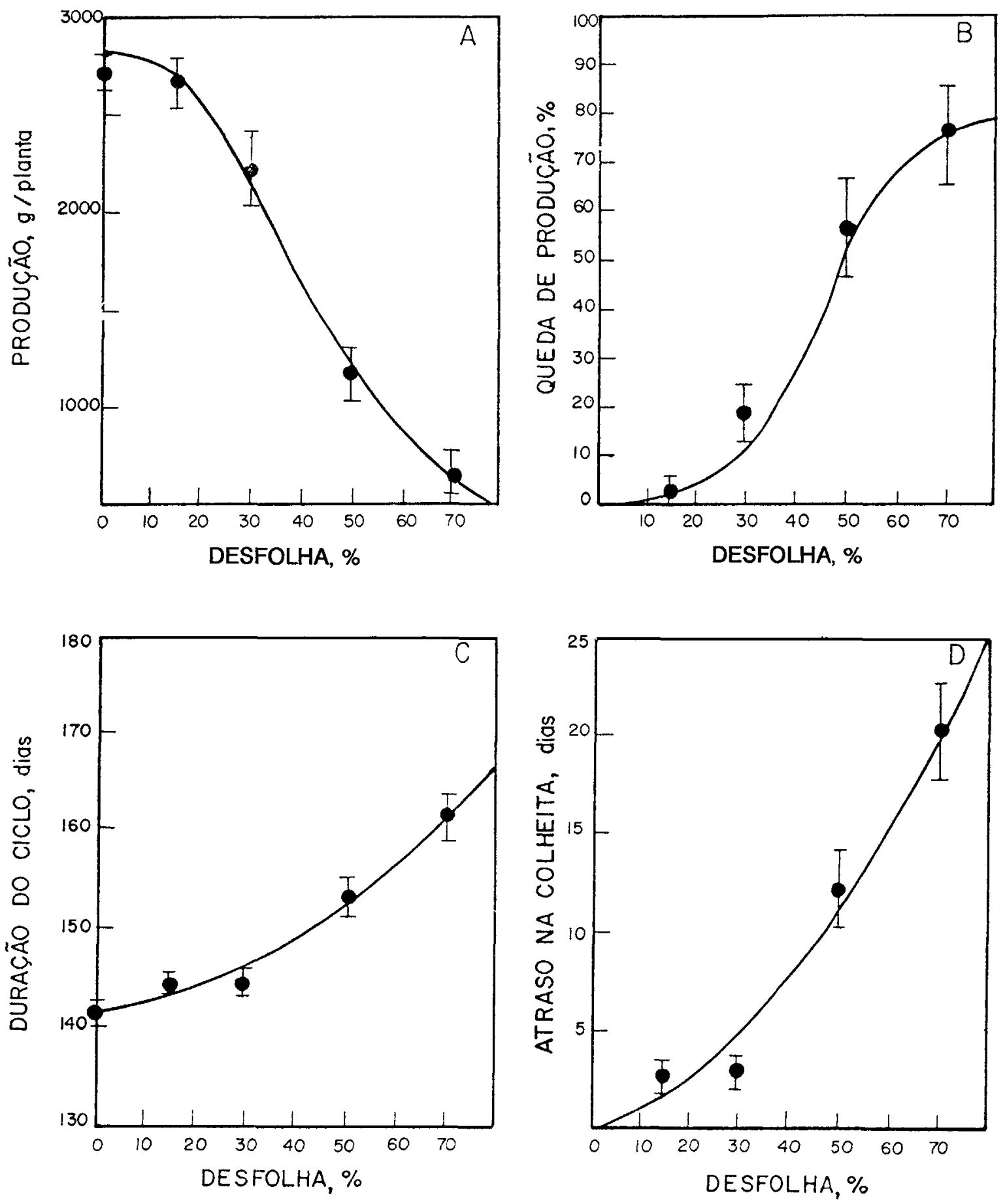

Figura 1. Valores observados médios e erro padrão da média de: A: produção; B: perda de produção; C: duração do ciclo e D: atraso na colheita em função do nível de desfolha e curvas obtidas por equaçòes empíricas para videira Niagara Rosada. 
no caso da desfolha de $70 \%$, e a duração do ciclo foi aumentada até em $\mathbf{2 0}$ dias, condicionando a uma colheita mais tardia.

Os níveis de perda de produção no experimento foram maiores que os encontrados na literatura, que sāo, no máximo, da ordem de 35\% (May et al., 1969, e Kliewer, 1970). Segundo Peterson \& Smart (1975), a manutençāo de seis folhas por ramo não afeta a produtividade e, nas condiçōes experimentais, notou-se que mesmo os tratamentos com cinco folhas por ramo não afetaram a produção.

No caso da produção, pelo teste de Duncan, não houve influência de anos, mas o mesmo não aconteceu com a duraçāo do ciclo. Na média, os três anos diferiram entre si, influenciados provavelmente pela época de poda, uma vez que o efeito das temperaturas médias na duração do ciclo não foi muito bem evidenciado, pois as temperaturas, medidas no posto meteorológico distante $300 \mathrm{~m}$ do experimento, variaram de $1^{\circ} \mathrm{C}$ apenas de um ano para outro.

$\mathrm{Na}$ figura 1 são mostrados os valores médios de: produção (Figura 1A), porcentagem de queda da produção (Figura 1B); duração do ciclo (Figura 1C) e atraso na colheita (Figura 1D), para os diferentes tratamentos.

Salientando-se que a desfolha foi artificial e não causada pelo ataque de pragas ou de patógenos, cujas possíveis interaçōes com o hospedeiro poderiam influenciar os resultados, notou-se redução acentuada da produção (Figura 1B), a partir dos tratamentos com 50 e $70 \%$ de desfolha, com valores de 56 e $77 \%$ respectivamente. Quanto ao atraso na colheita (Figura 1D), os tratamentos de desfolha de 70 e $50 \%$ mostraram um atraso de 20 e 12 dias respectivamente. Esses atrasos têm importância econômica, pois as colheitas do início de dezembro alcançam preços do produto até duas vezes superiores aos de janeiro (Pommer, 1989).

Pelos resultados, poder-se-ia esperar que a incidência moderada de doenças que reduzissem até $15 \%$ a área foliar da videira não afetaria a produtividade e a duraçāo do ciclo de 'Niagara Rosada'.

Para a tentativa de se relacionar nivel de desfolha com área foliar infectada por agentes patogênicos, para simulação do efeito de seu ataque nas folhas sobre a produção e a duração do ciclo da videira 'Niagara Rosada', foram desenvolvidas funçōes matemáticas empíricas que permitissem interpolaçāo e/ou previsão.

Segundo Pereira \& Arruda (1987), é mais importante a função que o rigor e a sofisticação do método de ajuste e, em determinadas situações, os métodos menos exigentes permitem o ajuste. À luz desse pensamento, foi utilizado um programa computacional (Zullo Jr. \& Arruda, 1987) que possibilitou o ajuste de 17 modelos de equaçōes em uso na Agronomia. Mediante o valor do coeficiente de correlação e da tendência da dispersão dos dados num gráfico de coordenadas cartesianas, foram desenvolvidas funções que melhor descreviam o efeito da desfolha na produção e na duração do ciclo.

Quadro 1. Valores de produção e duração do ciclo da videira 'Niagara Rosada' para diferentes níveis de desfolha, na região de Jundiaí (SP), durante três anos agrícolas

\begin{tabular}{|c|c|c|c|c|c|c|c|c|}
\hline \multirow{2}{*}{$\begin{array}{l}\text { Tratamento } \\
\text { (Desfolha) }\end{array}$} & \multicolumn{2}{|c|}{1988} & \multicolumn{2}{|c|}{1989} & \multicolumn{2}{|c|}{1990} & \multicolumn{2}{|c|}{ Média } \\
\hline & Produçāo & Ciclo & Produção & Ciclo & Produção & Ciclo & Produção & Ciclo \\
\hline$\%$ & g/planta & dias & g/planta & dias & g/planta & dias & g/planta & dias \\
\hline 70 & $1040 \mathrm{~b}$ & $170 a$ & $500 \mathrm{~d}$ & $154 a$ & $436 c$ & $159 a$ & $659 d$ & $161 \mathrm{a}$ \\
\hline 50 & $1562 b$ & $160 \mathrm{~b}$ & $1150 \mathrm{c}$ & $147 \mathrm{~b}$ & $820 \mathrm{c}$ & $152 b$ & $1177 \mathrm{c}$ & $153 b$ \\
\hline 30 & $2232 a$ & $147 \mathrm{c}$ & $1850 \mathrm{~b}$ & $141 \mathrm{c}$ & $2250 \mathrm{~b}$ & $145 c$ & $2111 b$ & $144 c$ \\
\hline 15 & $2426 a$ & $147 \mathrm{c}$ & $2590 a$ & $141 c$ & $3084 a$ & $143 c$ & $2700 \mathrm{a}$ & $144 c$ \\
\hline 0 & $2428 \mathrm{a}$ & $144 c$ & $2996 a$ & $137 \mathrm{c}$ & $2770 \mathrm{ab}$ & $141 c$ & $2731 a$ & $141 d$ \\
\hline C.V. $(\%)$ & 21,9 & 2,4 & 23,4 & 2,6 & 22,7 & 2,5 & 22,6 & 2,5 \\
\hline
\end{tabular}

Médias seguiđas da mesma letra não diferem estatisticamente pelo teste de Duncan a $5 \%$. 
No quadro 2 são apresentadas as equações de estimativa que melhor se ajustaram para avaliar o efeito da desfolha na produção, na queda de produção, na duração do ciclo e no atraso na colheita.

$O$ modelo de equação que melhor se ajustou aos valores médios de produção foi a logística negativa (Figura 1A) e, para queda de produção, a logística (Figura 1B). Optou-se para os valores assintóticos de $2.800 \mathrm{~g} /$ planta e de $80 \%$ para as equaçōes de estimativa da produção e da queda de produção, por serem os que melhor ajuste (valor mais alto do coeficiente de correlação) mostraram para as curvas.
No caso da duração do ciclo e do atraso na colheita, por serem basicamente o mesmo parâmetro, o melhor ajuste encontrado foi a função quadrática. Pode-se notar (Quadro 2) que os coeficientes das equaçōes para $x$ e $x^{2}$ são o mesmo, diferenciando-se apenas no coeficiente 141,33 para duração do ciclo e 0,326 para atraso na colheita.

As equaçōes apresentadas são válidas para os níveis de desfolha no intervalo 0 e $70 \%$, devendo as extrapolaçōes ser feitas com cuidado, pois, fora desse intervalo, nada garante que a mesma relação se mantenha.

Quadro 2. Equaçōes de estimativa da produção, queda de produção, duração do ciclo e atraso na colheita em função do nível de desfolha (x) para a videira 'Niagara Rosada'

Parâmetro
Coeficiente

de correlação
Equação
a. Produção (g/planta)
Logística negativa
0,999
Logística
$-0,984$
b. Queda de produção (\%)
Quadrática
0,990
c. Duração do ciclo (dias)
Quadrática

$$
\begin{aligned}
& \mathrm{Y}=2800 /\left[1+(\mathrm{x} / 46,185)^{2,94}\right] \\
& \mathrm{Y}=80 /[1+271,385 . \operatorname{EXP}(-0,126 \mathrm{x})] \\
& \mathrm{Y}=141,33+0,4016 \mathrm{x}+0,00349 \mathrm{x}^{2} \\
& \mathrm{Y}=0,326+0,04016 \mathrm{x}+0,00349 \mathrm{x}^{2}
\end{aligned}
$$$$
0,990
$$

\section{CONCLUSÕES}

1. A diminuição da área foliar pela desfolha artificial de $70 \%$ levou a uma queda de produção em até $77 \%$ e a um aumento de vinte dias na duração do ciclo. A redução de $15 \%$ da área foliar não afetou a produção de uvas, aumentando muito pouco a duração do ciclo.

2. As curvas da função logística foram as que melhor se ajustaram para avaliar o efeito da desfolha na produção e da função quadrática para a duração do ciclo.

\section{REFERÊNCIAS BIBLIOGRÁFICAS}

BLEDSOE, A.M.; KLIEWER, W.M. \& MAROIS, J.J. Effects of timing and severity of leaf removal on yield and fruit composition of sauvignon blanc grapevines. American Journal of Enology and Viticulture, Davis, 39:49-54, 1988.

KLIEWER, W.M. Effect of time and severity of defoliation on growth and composition of 'Thompson seedless' grapes. American Journal of Enology and Viticulture, Davis, 21:37-47, 1970.
KLIEWER, W.M. \& ANTCLIFF, A.J. Influence of defoliation leaf darkening and cluster shadding on the growth and composition of sultana grapes. American Journal of Enology and Viticulture, Davis, 21:26-36, 1970.

MAY, P.; SHAULIS, N.J. \& ANTCLIFF, A.J. The effect of controlled defoliation in sultana vine. American Journal of Enology and Viticulture, Davis, 20:237-250, 1969.

PARRA, J.P.P. Bioecologia de Perileucoptera coffeella (Guérin-Mèneville, 1842) (Lepidoptera-Lyonetidae) em condiçōes de campo. Piracicaba, 1975, 114p. Tese (Doutorado) - ESALQ-USP, 1975.

PEREIRA, A.R. \& ARRUDA, H.V. Ajuste prático de curvas na pesquisa biológica. Campinas, Fundação Cargill, 1987. 50p.

PEIERSON, J.R. \& SMART, R.E. Foliage removal effects on 'Shiraz' grapevines. American Journal of Enology and Viticulture, Davis, 26:119-124, 1975.

POMMER, C.V. Produção e comercialização de uvas em Sāo Paulo. Toda Fruta, São Caetano do Sul, 4:(35):23-26, 1989.

ZULLO JÚNIOR, J. \& ARRUDA, F.B. Programa computacional para ajuste de equaçóes em dados experimentais. Campinas, Instituto Agronômico, 1987. 31p. (Boletim técnico, 113) 